\title{
Hot Tearing Susceptibility of AXJ530 Alloy Under Low-Frequency Alternating Magnetic Field
}

\author{
Xudong $\mathrm{Du}^{1,2} \cdot$ Feng Wang ${ }^{1,2} \cdot$ Zhi Wang $^{1,2} \cdot$ Xingxing $\mathrm{Li}^{1,2} \cdot$ Zheng Liu $^{1,2} \cdot$ Pingli Mao ${ }^{1,2}$
}

Received: 24 October 2019 / Revised: 24 December 2019 / Published online: 26 March 2020

(C) The Chinese Society for Metals (CSM) and Springer-Verlag GmbH Germany, part of Springer Nature 2020

\begin{abstract}
Herein, a hot tearing measured system with external excitation coil and a differential thermal analysis system with applied magnetic field were used to study the effects of low-frequency alternating magnetic field on the solidification behavior and hot tearing susceptibility (HTS) of the AXJ530 alloy under different magnetic field parameters. The hot tearing volume of the castings was measured via paraffin infiltration method. The microstructure of the hot tearing zone of the casting was observed using optical microscopy and scanning electron microscopy, and the phase composition was analyzed using X-ray diffraction and energy depressive spectroscopy. The experimental results show that the solidification interval of AXJ530 alloy was shortened and the dendrite coherency temperature of the alloy decreased with the increase in frequency of alternating magnetic field. Under appropriate magnetic field parameters, the electromagnetic force could enhance the convection in the melt to promote the flow of the residual liquid phase, refine the microstructure, and optimize the feeding channel in the late solidification stage, which reduced the HTS of the alloy. However, when the magnetic field frequency was increased to $15 \mathrm{~Hz}$, the induced current generated excessive Joule heat to the melt. At this time, the thermal action of the magnetic field coarsened the microstructure of the alloy, resulting in an increase in HTS of the alloy.
\end{abstract}

Keywords AXJ530 alloy $\cdot$ Hot tearing susceptibility $\cdot$ Alternating magnetic field $\cdot$ Microstructure

\section{Introduction}

Magnesium alloys are not only rich in reserves but also display good specific strength and stiffness. Therefore, they are employed in the fields of aerospace and lightweight of automotive structural parts [1-3]. Several commercial magnesium alloys have been widely used such as AZ91, AM50, and EW75. Among them, AXJ530 (Mg-5Al-3Ca-0.17Sr) alloy has the richest phase composition and best high-temperature mechanical properties, creep resistance, and alkali corrosion resistance $[4,5]$. Also, AXJ530 alloy has lower cost and greater practical value than the RE-containing magnesium alloys. However, the AXJ530 alloy has a high hot

Available online at http://link.springer.com/journal/40195.

Feng Wang

wf9709@126.com

1 College of Materials Science and Engineering, Shenyang University of Technology, Shenyang 110870, China

2 Key Laboratory of Magnesium Alloys and the Processing Technology of Liaoning Province, Shenyang 110870, China tearing susceptibility (HTS), owing to which alloy has low yield in actual production and severely restricts its applications [6].

Hot tearing as a common magnesium alloy casting defect severely constrains the development of its lightweight applications. Therefore, extensive research work has been conducted to address the issue. Cao and Kou [7] studied the $\mathrm{Mg}-\mathrm{Al}-\mathrm{Ca}$ alloys and found that $\alpha-\mathrm{Mg}+(\mathrm{Mg}, \mathrm{Al})_{2} \mathrm{Ca}$ and $\alpha-$ $\mathrm{Mg}+\mathrm{Mg}_{2} \mathrm{Ca}$ eutectic structures could repair the cracks and even heal the cracks. As the volume fraction of the eutectic phase in the alloy increased, the HTS of the alloy significantly decreased. Wang et al. [8] explored the effect of Ca content on the HTS of $\mathrm{Mg}-5 \mathrm{Al}-x \mathrm{Ca}(x=0.5,1,2,3,4$, and $5)$ alloys. The results show that the eutectic phase content of the alloys increased with the increase in Ca content and HTS of the alloys decreased continuously. Among them, the $\mathrm{Mg}-5 \mathrm{Al}-4 \mathrm{Ca}$ alloy had the lowest HTS. When the Ca element content reached $5 \mathrm{wt} \%$, the HTS of the alloy increased due to the increase in the grain size of the alloy and the number of Ca-containing brittle phases in the microstructure. Also, the previous works [9-11] have shown that the rare earth elements play an important role in improving the 
properties of the magnesium alloy. Additionally, it has been proven that the addition of rare earth elements can reduce the HTS of alloys [12-14]. Wei [13,14] found that as the $\mathrm{Zn}$ and $\mathrm{Y}$ content increased, the grain refinement led to a decrease in the HTS of alloy, and it was possible to change the phase composition by controlling the ratio of $\mathrm{Zn}$ and $\mathrm{Y}$ to reduce the HTS of the alloy. However, the above methods for reducing the HTS of the alloy by the addition of alloying elements or rare earth elements have disadvantages such as high alloy cost, strict element ratio, and high requirement of the melting process.

In recent years, it has been reported that a magnetic field can purify the melt, refine the grains, and improve the as-cast microstructure and properties of the alloy [15-17]. Furthermore, compared with previously mentioned methods, the magnetic field has the advantages such as simple operation, easy control of parameters, clear effect, and no introduction of impurities. Cao [18] studied the solidification process of $\mathrm{Sn}-50 \mathrm{wt} \% \mathrm{~Pb}$ alloy under traveling magnetic field (TMF) via synchrotron radiation $\mathrm{X}$-ray photography and found that magnetic field could enhance the convection in the melt. Also, solute enrichment under magnetic field could make dendrites fuse or break. Wang et al. [19] investigated the effects of pulsed magnetic field on the solidified microstructure of an AZ91D magnesium alloy. The results show that the average grain size was significantly refined under the pulsed magnetic field. Till date, the research has focused on the effects of magnetic fields on the solidification structure and mechanical properties of aluminum alloys and some low melting point alloys. However, there are limited studies on the solidification behavior and hot tearing susceptibility of magnesium alloys.

There are several kinds of magnetic fields, among which the effect of alternating magnetic field is clear and the operation and application are the simplest [20-24]. Therefore, herein, alternating magnetic field was chosen and AXJ530 alloy with high HTS was selected as the research object. The effects of alternating magnetic fields with different frequencies on the solidification behavior and HTS of AXJ530 alloy were studied, and the thermal tearing mechanism of the alloy under the action of alternating magnetic field was preliminarily investigated.

\section{Experimental}

\subsection{Hot Tearing Experiment}

The commercial AXJ530 (Mg-5Al-3Ca-0.17Sr) alloy was melted in an electric resistance furnace under a mixed protective atmosphere of $0.03 \% \mathrm{SF}_{6}$ and $\mathrm{N}_{2}$. After the alloy was completely melted, the melt was subjected to the slag removal treatment and maintained at $700{ }^{\circ} \mathrm{C}$ for $30 \mathrm{~min}$. When the molten metal reached the casting temperature, it was poured into a "T-shaped" hot tearing mold of $250{ }^{\circ} \mathrm{C}$. The T-shaped hot tearing measured system $[25,26]$ with external magnetic field is shown in Fig. 1. An excitation coil connected to the variable frequency power supply was placed in the main body and the hot section of the "T-shaped" hot tearing mold. Studies $[21,27]$ have shown that the frequency of the low-frequency alternating magnetic field usually does not exceed $30 \mathrm{~Hz}$, and the current frequency of about $10 \mathrm{~Hz}$ leads to the most prominent and best electromagnetic effect. Therefore, in combination with the mold equipment used in this experiment, the coil applied a low-frequency alternating magnetic field to the molten metal at a frequency of $5 \mathrm{~Hz}$, $10 \mathrm{~Hz}$, and $15 \mathrm{~Hz}$ during the solidification of the alloy. At the same time, the system measured and collected the temperature and shrinkage stress of the alloy during the solidification process through the thermocouple and the stress

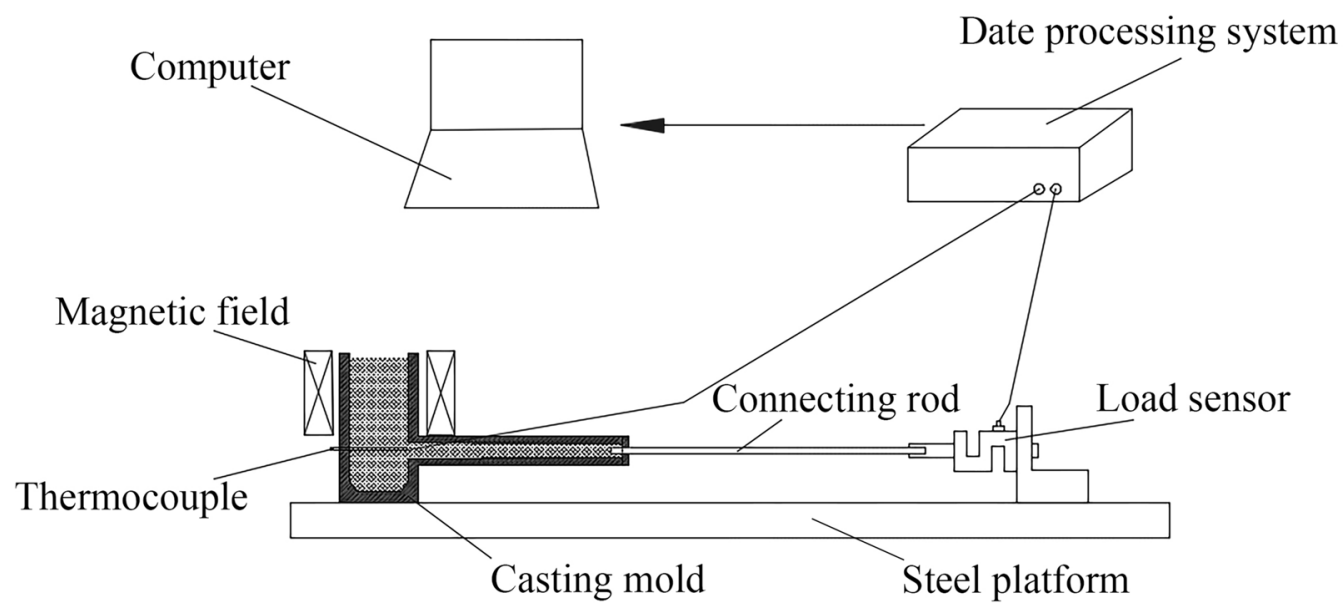

Fig. 1 Hot tearing measured system with applied magnetic field 
sensor in order to obtain the hot tearing curves of the alloys under the action of low-frequency alternating magnetic field. The hot tearing volume of the casting was measured using the paraffin infiltration method [28] to visually demonstrate the hot tearing susceptibility of the alloys.

\subsection{Differential Thermal Analysis (DTA)}

Solidification is a complex process that is accompanied by phase change thermodynamics, solidification kinetics, and various transport phenomena [29]. At the same time, the solidification process of the alloy has several effects on the hot tearing behavior of the alloy. Therefore, it is of great significance to study the solidification behavior of the alloy under low-frequency alternating magnetic field for analyzing the hot tearing mechanism under this condition. In this study, the differential thermal analysis (DTA) system with an external magnetic field was employed to measure and collect various types of solidification information of the alloy under the action of a low-frequency alternating magnetic field. The experimental setup of the system is shown in Fig. 2. The graphite crucible was placed in the center of the excitation coil externally connected to the variable frequency power supply. The current intensity and frequency of the coil were adjusted by the variable frequency power supply to control the parameters such as the strength and frequency of the magnetic field. Each sample weighed $150 \mathrm{~g}$ and was applied with the same magnetic field parameters as the hot tearing experiment. Two thermocouples were placed at the center and edge of the graphite crucible to record the temperature of the molten metal at the corresponding locations during solidification. The initial temperature of the molten metal was $700{ }^{\circ} \mathrm{C}$, and it was allowed to cool naturally in the air. As the metal liquid at the edge cooled quickly and solidified first, it had a temperature difference with the molten metal at the center position whose cooling rate was slow.

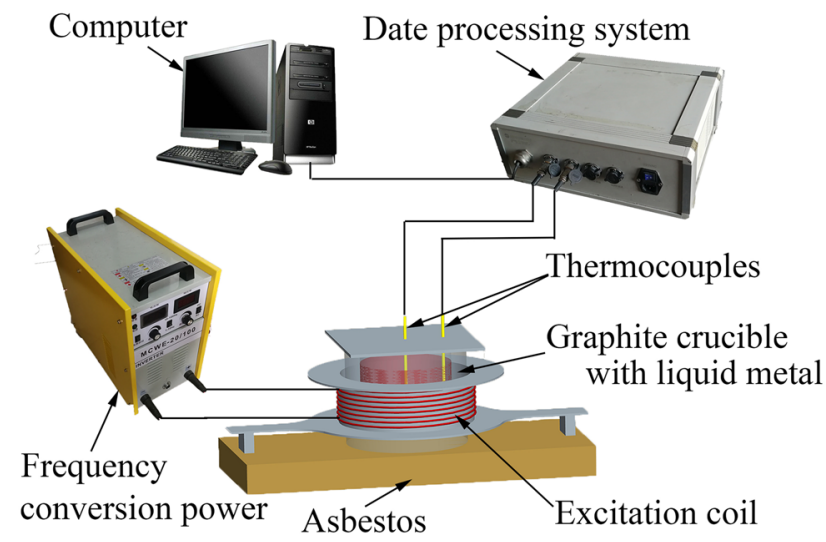

Fig. 2 Differential thermal analysis experimental system with magnetic field
Also, the rapid thermal conductivity of the solids increased the temperature difference between the two positions. However, when the dendrites at the two locations grew to overlap with each other, the heat transfer rate of the two locations increased and the temperature difference started to decrease. Therefore, the temperature corresponding to the extreme point of the temperature difference curve was defined as the dendrite coherency temperature $\left(T_{\text {coh }}\right)$ of the alloy.

Herein, the temperature change information of AXJ530 alloy under different conditions collected with the solidification experiment was combined with the cracking susceptibility coefficient $\left(\mathrm{CSC}_{\mathrm{t}}\right)$ prediction model to analyze the HTS of the alloys under different conditions. The Clyne-Davies model is one of the most classical hot tearing prediction models in the study of hot crack behavior of today's alloys [30]. The researchers believe that the alloy melt is in a pastelike state in the final stage of solidification. (The alloy solid fraction is between 90 and $99 \%$.) When the solidification shrinkage produced cracks, there was not enough liquid metal to supply cracks, which eventually led to hot cracks. Therefore, the vulnerable time $\left(t_{\mathrm{V}}\right)$ is defined as the time when the solid fraction of the alloy is between 90 and $99 \%$. While the crack generated when the solid fraction of the alloy is between 40 and $90 \%$ can be healed by a large amount of molten metal; hence, this time is defined as the stressrelief time $\left(t_{\mathrm{R}}\right)$. The Clyne-Davies model is a measure of the hot tearing susceptibility of different alloys by the ratio of the two, and the $\mathrm{CSC}_{\mathrm{t}}$ is written as

$\mathrm{CSC}_{\mathrm{t}}=\frac{t_{\mathrm{V}}}{t_{\mathrm{R}}}=\frac{t_{0.99}-t_{0.9}}{t_{0.9}-t_{0.4}}$.

\subsection{Microstructure Analysis}

The samples were taken from the hot spot of the castings and were polished (as shown in Fig. 3). Then, the samples were etched using $4 \% \mathrm{HNO}_{3}$ ethanol solution with holding time of 3-4 s. The microstructure and fracture morphology of the samples were observed via optical microscopy (OM, Zeiss Axio Observer A1) and scanning electron microscopy

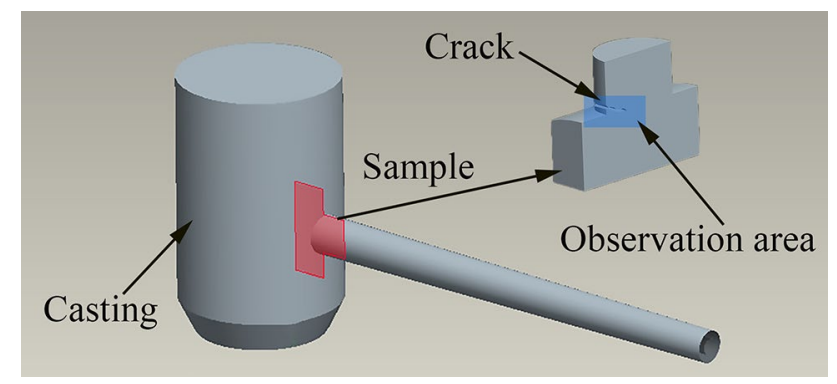

Fig. 3 Selection and preparation method of the samples 
(SEM, Hitachi S-3400N). The phase identification was performed using X-ray diffractometer (Rikakn D/maxr) with $\mathrm{Cu}$ $K \alpha$ radiation generated at $40 \mathrm{kV}$ and $30 \mathrm{~mA}$, and a scan rate of $2\left(^{\circ}\right) / \mathrm{min}$ in a $2 \theta$ range of $20^{\circ}-90^{\circ}$. At the same time, the phase composition was determined via energy depressive spectroscopy (EDS).

\section{Results and Discussion}

\subsection{Hot Tearing Curves and Cracks Volume}

Figure 4 shows the temperature-time-stress curves of the AXJ530 alloy under different frequency electromagnetic fields and the macro-cracks of the "T-shaped" castings are shown in Fig. 5. As the solidification progressed, the shrinkage stress was generated and the stress value increased with time. When the hot cracks were formed in the castings, the stress curves collected by the system showed a significant drop due to the release of the shrinkage stress at this time.
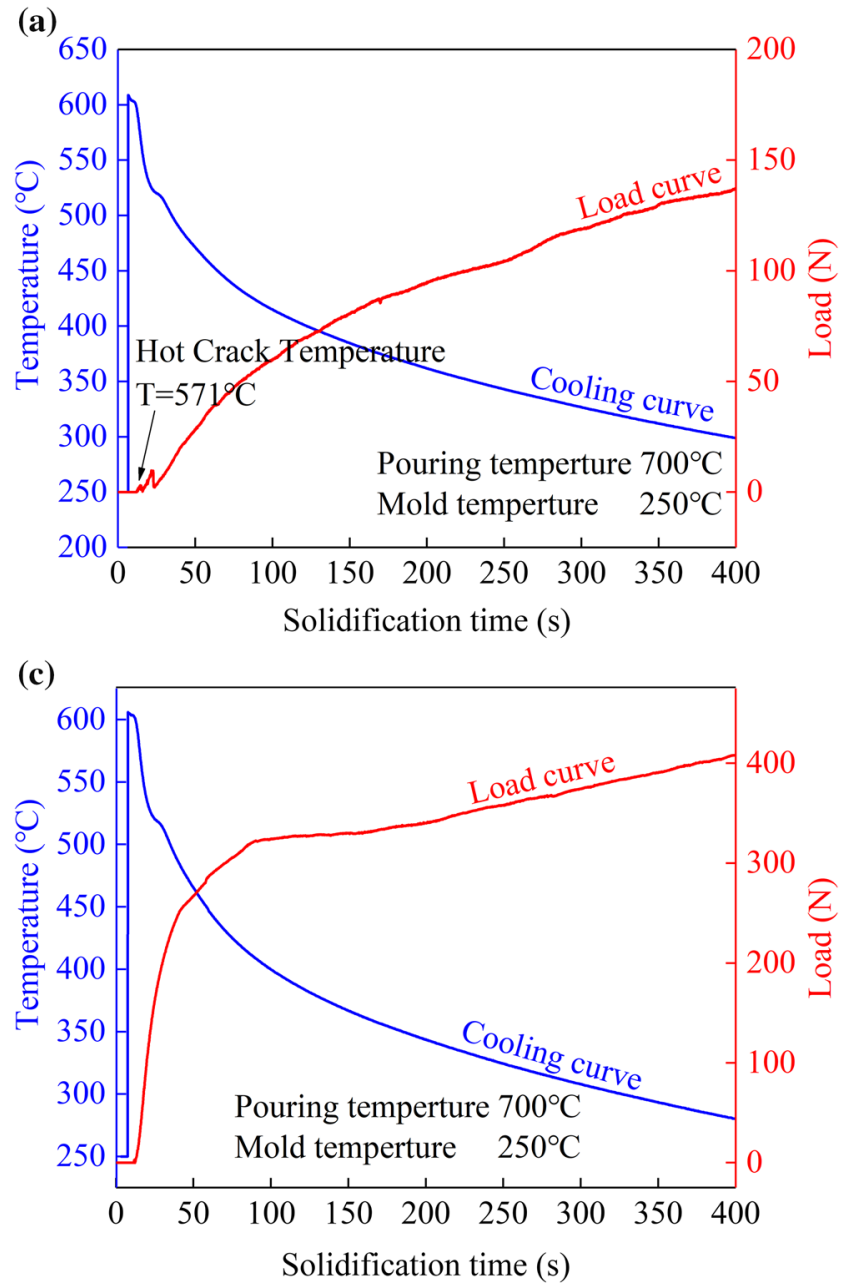

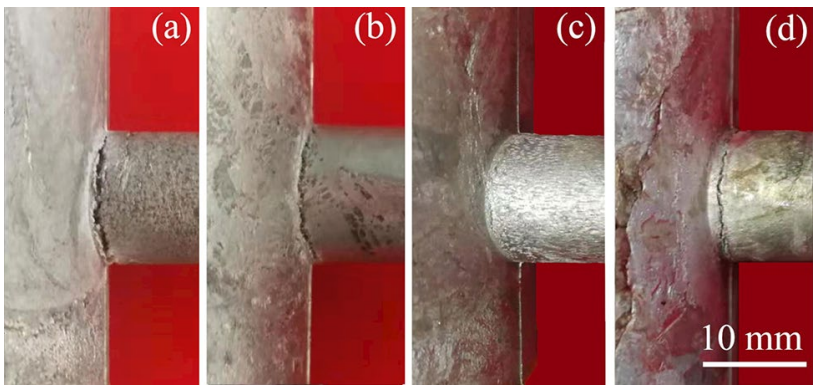

Fig. 5 Macro-cracks of the casting under different magnetic field conditions: a $0 \mathrm{~A}, 0 \mathrm{~Hz}$; b $10 \mathrm{~A}, 5 \mathrm{~Hz} ; \mathbf{c} 10 \mathrm{~A}, 10 \mathrm{~Hz}, \mathbf{d} 10 \mathrm{~A}, 15 \mathrm{~Hz}$

The intensity of crack propagation and the HTS of the alloy can be preliminarily judged by combining the macro-crack with the information about temperature, stress, and time in the hot tearing curves. The stress curve of AXJ530 alloy without magnetic field showed two significant drops near $571{ }^{\circ} \mathrm{C}$, and the casting had clear cracks. Hence, it can be concluded that the alloy had a high HTS under these

(b)

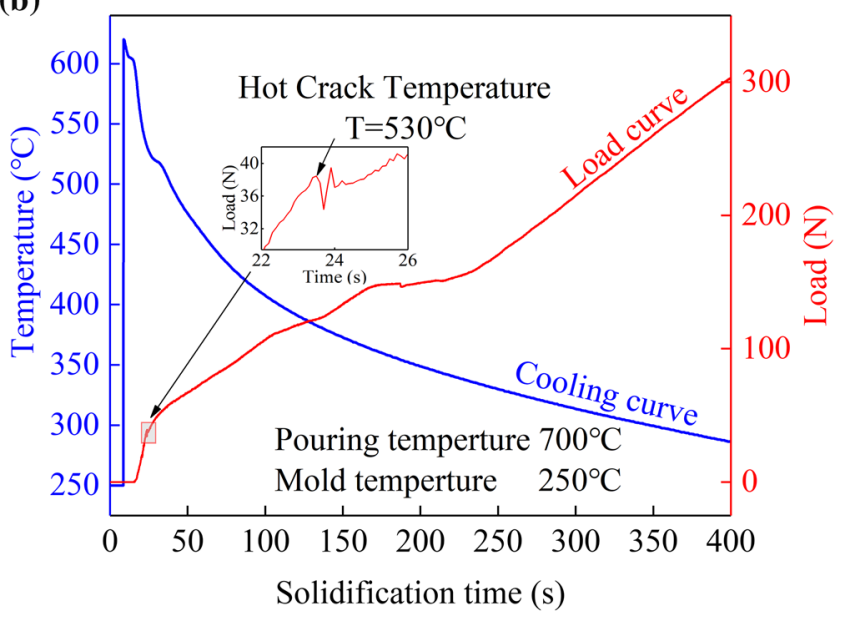

(d)

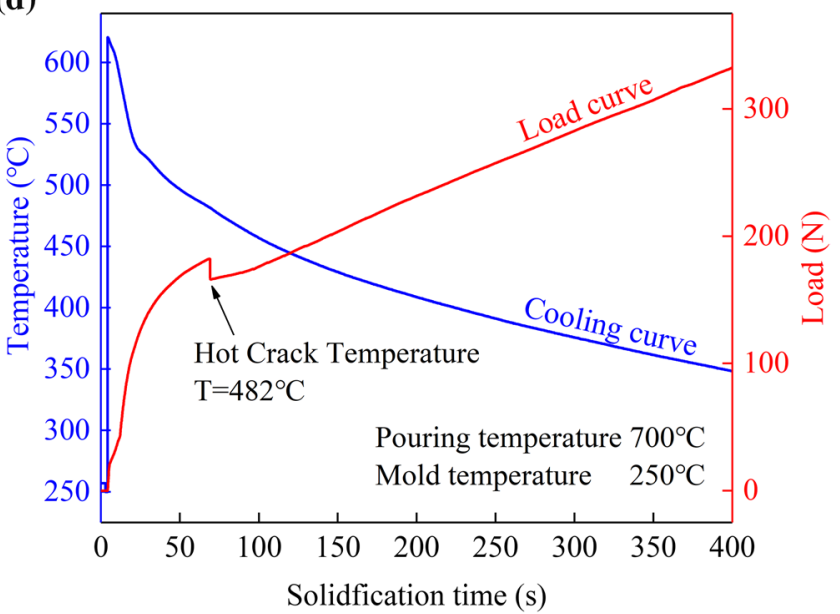

Fig. 4 Hot tearing curves of AXJ530 alloy under different magnetic field conditions: a 0 A, $0 \mathrm{~Hz}$; b $10 \mathrm{~A}, 5 \mathrm{~Hz}$; c $10 \mathrm{~A}, 10 \mathrm{~Hz}$, d $10 \mathrm{~A}, 15 \mathrm{~Hz}$ 
conditions. After the application of low-frequency alternating magnetic field, the amount of stress release during alloy solidification was reduced, and the ability of the alloy to resist shrinkage stress was enhanced. Among these, when the electromagnetic field with a current parameter of $10 \mathrm{~A}$ $10 \mathrm{~Hz}$ was applied, the stress curve grew smoothly without significant stress drop, and the surface of the casting had no substantial clear macro-cracks. However, when the current frequency was increased to $15 \mathrm{~Hz}$, the stress curve displayed a drop at the temperature of $482{ }^{\circ} \mathrm{C}$ and cracks appeared again on the surface of the casting. After the application of low-frequency alternating magnetic field to the solidification process of the alloy, the stress curves of the alloys tended to be overall smooth. But, after the magnetic field frequency reached $15 \mathrm{~Hz}$, the cracks occurred again. With regard to stress at the time of hot tearing, when the current frequency was $15 \mathrm{~Hz}$, the stress when the alloy was hot cracked was greater than that when the current frequency was $5 \mathrm{~Hz}$, which means that its hot tearing tendency was less than when the current frequency is $5 \mathrm{~Hz}$. Therefore, according to the cracks on the castings and hot tearing curves, it can be preliminarily judged that the ability of the alloys to resist hot tearing was enhanced under the action of lowfrequency alternating magnetic field. With the increase in current frequency, the HTS of the alloys first decreased and then increased, and the alloy had the lowest HTS at the current frequency of $10 \mathrm{~Hz}$.

The hot tearing volume of the castings measured via paraffin infiltration method is shown in Fig. 6. The principle of this method is shown in Eq. (2). The weights before and after paraffin penetration are marked as $M_{1}$ and $M_{2}$, respectively, and $\rho$ is the density of paraffin. When no magnetic field was applied, the cracks of the castings had the largest volume of

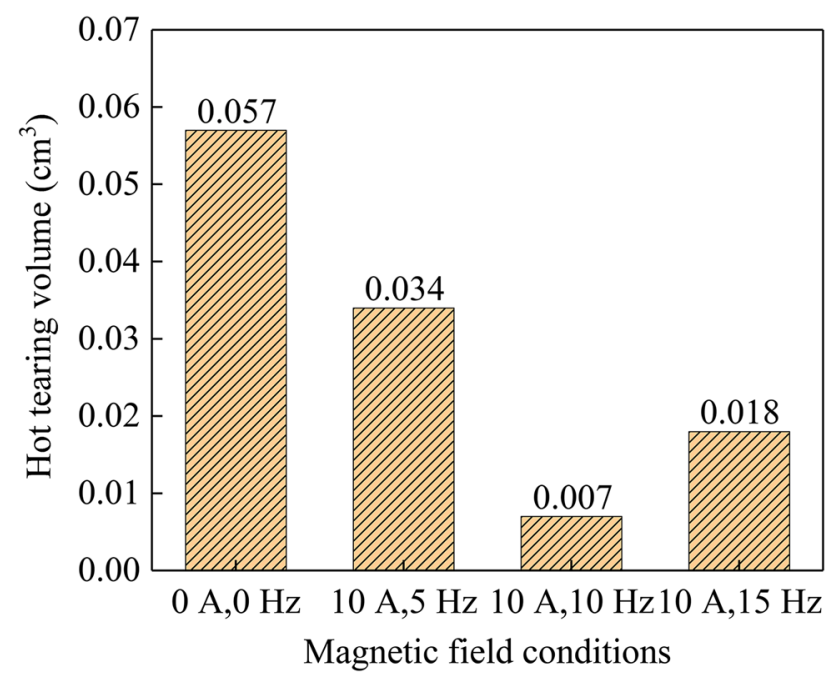

Fig. 6 Volume of cracks of casting under different magnetic field conditions
$0.057 \mathrm{~cm}^{3}$. The hot tearing volume of the castings was significantly reduced under the action of alternating magnetic field, and its trend of change with frequency was basically the same as the trend for hot tearing curve. At the magnetic field frequency of $10 \mathrm{~Hz}$, the casting had the smallest hot tearing volume of $0.007 \mathrm{~cm}^{3}$.

$V=\frac{\left(M_{2}-M_{1}\right)}{\rho}$.

\subsection{Analysis of Solidification Behavior}

Figure 7 shows the thermal analysis curves of the AXJ530 alloy. During the alloy solidification, the temperature of the molten metal decreased with time. However, when the phase in the alloy precipitated and released latent heat, the slope of the solidification temperature curve suddenly changed. Therefore, the temperature corresponding to the starting point of the first mutation of the derivative curve is defined as the liquidus of the alloy, and the temperature at the point where the last mutation ends is defined as the solidus of the alloy. According to the study of the solidification path of $\mathrm{Mg}-\mathrm{Al}-\mathrm{Ca}$ alloy by Cao [7] and Suzuki [31] in combination with X-ray diffraction (XRD) analysis map (see Fig. 8), the precipitation reactions corresponding to the three main exothermic peaks in Fig. 7 were determined as follows: $\alpha$ $\mathrm{Mg}$ precipitation reaction (A peak), $\mathrm{L} \rightarrow \alpha-\mathrm{Mg}+\mathrm{C} 36((\mathrm{Mg}$, $\left.\mathrm{Al})_{2} \mathrm{Ca}\right)$ (B peak), and $\mathrm{L} \rightarrow \alpha-\mathrm{Mg}+\mathrm{C} 36+\mathrm{C} 14\left(\mathrm{Mg}_{2} \mathrm{Ca}\right)(\mathrm{C}$ peak). The solidification temperature information of the AXJ530 alloy is summarized in Table 1. The experimental results show that the precipitation temperature of $\alpha-\mathrm{Mg}$ in the AXJ530 alloy was $624^{\circ} \mathrm{C}$ under the action of no magnetic field. The precipitation temperature of $\alpha-\mathrm{Mg}$ decreased significantly after the application of low-frequency alternating magnetic field, and the precipitation temperature of $\alpha$ $\mathrm{Mg}$ was the lowest at $608{ }^{\circ} \mathrm{C}$ when the current frequency was $10 \mathrm{~Hz}$. However, the solidus of the alloys did not change much. The alloy solidification temperature range was clearly shortened under the action of the magnetic field, and the temperature could be reduced by up to $13{ }^{\circ} \mathrm{C}$ as compared with the results for non-magnetic field.

The dendrite coherency temperature $\left(T_{\text {coh }}\right)$ is also an important factor affecting the HTS of the alloy. Studies [30, 32] have shown that liquid-phase flow is not substantially hindered, and the melt is in a free feeding phase until the $T_{\text {coh }}$ is reached. However, when the melt temperature reached $T_{\text {coh }}$, the crystal skeleton was basically composed. The melt feeding mode changed from free feeding to intergranular feeding, which increased the difficulty of feeding, and the cracks were more likely to occur. Figure 9 shows the DTA curves of the AXJ530 alloy under different conditions, as 

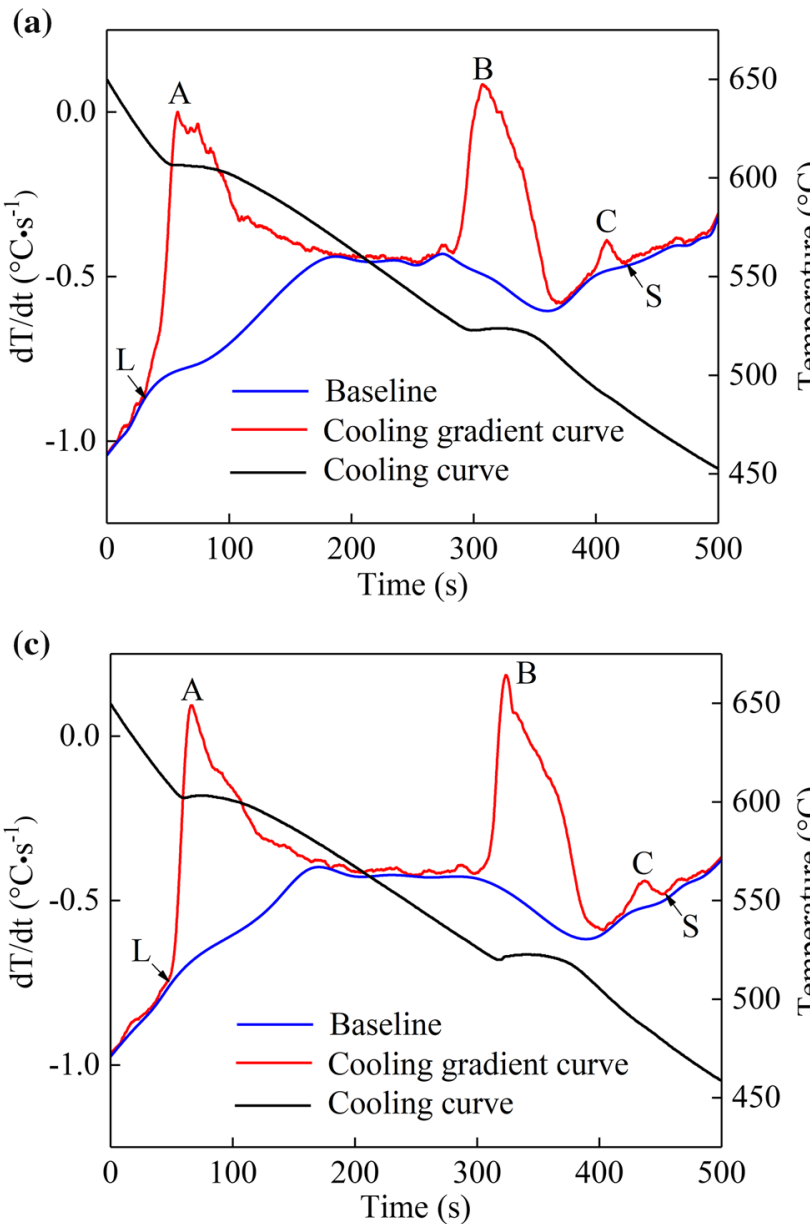
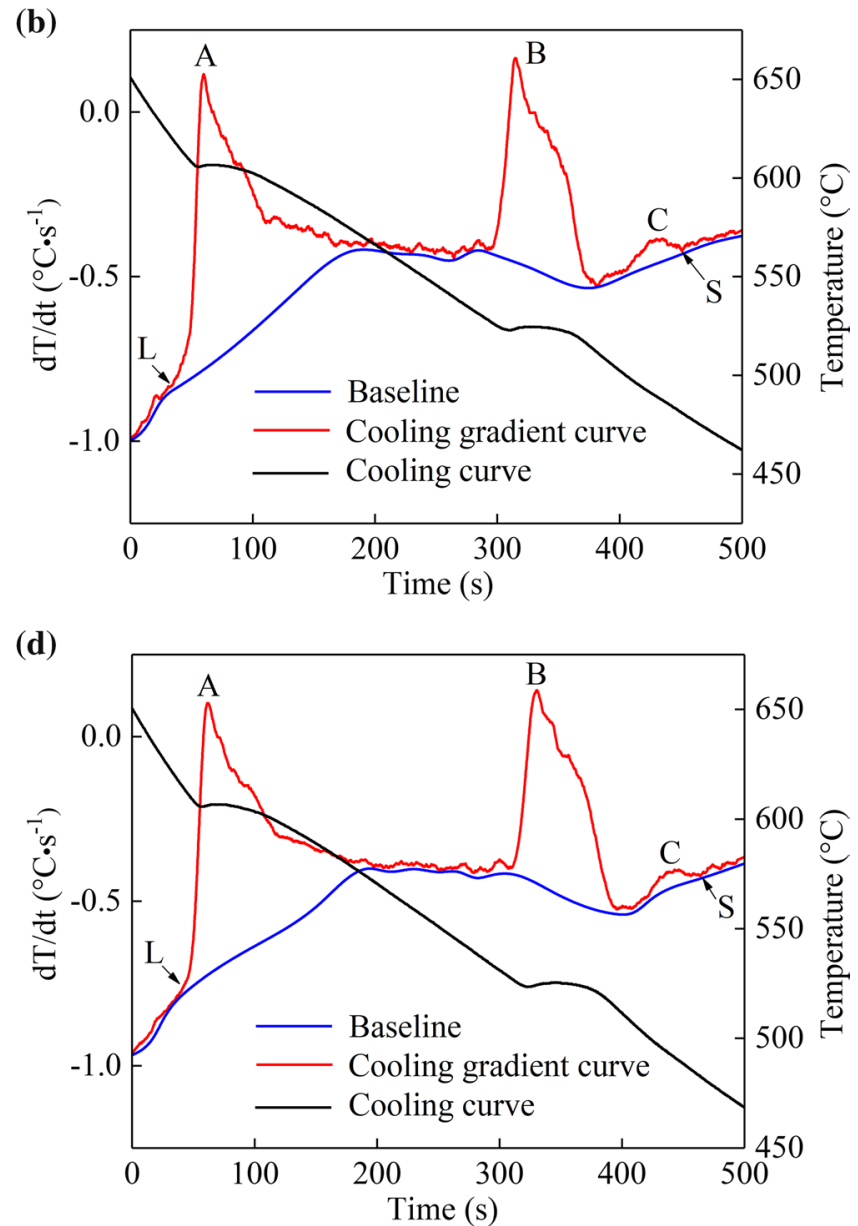

Fig. 7 Solidification curves of AXJ530 alloy under different magnetic field conditions: a 0 A, $0 \mathrm{~Hz}$; b $10 \mathrm{~A}, 5 \mathrm{~Hz}$; c $10 \mathrm{~A}, 10 \mathrm{~Hz}$, d $10 \mathrm{~A}, 15 \mathrm{~Hz}$

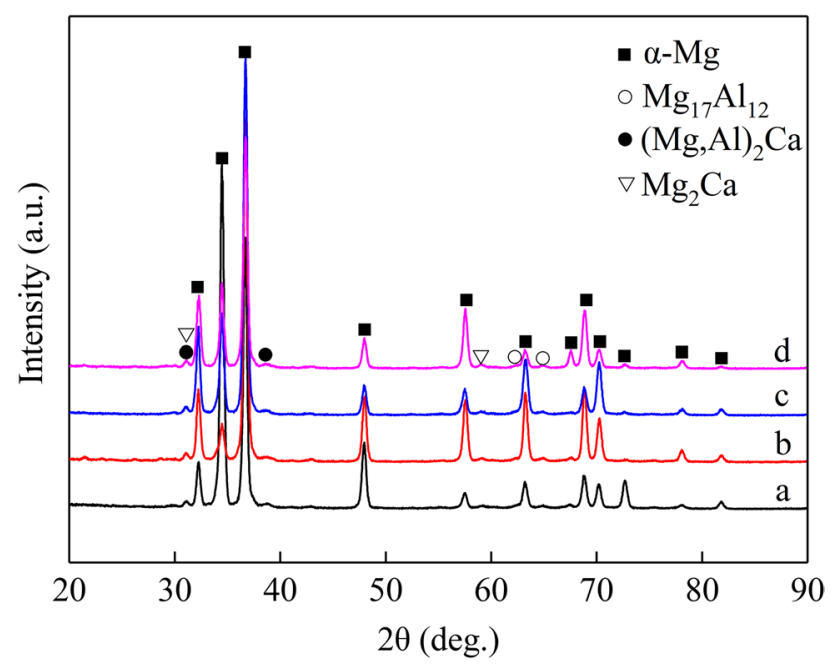

Fig. 8 XRD spectra of AXJ530 alloy under different magnetic field conditions: a $0 \mathrm{~A}, 0 \mathrm{~Hz}$; b $10 \mathrm{~A}, 5 \mathrm{~Hz} ; \mathbf{c} 10 \mathrm{~A}, 10 \mathrm{~Hz}, \mathbf{d} 10 \mathrm{~A}, 15 \mathrm{~Hz}$ measured by the DTA experiments. The figures show the cooling curves at the different positions of the molten metal
Table 1 Solidification temperature information of AXJ530 alloy

\begin{tabular}{llll}
\hline $\begin{array}{l}\text { Magnetic field } \\
\text { conditions }\end{array}$ & Liquidus $\left({ }^{\circ} \mathrm{C}\right)$ & Solidus $\left({ }^{\circ} \mathrm{C}\right)$ & $\Delta T\left({ }^{\circ} \mathrm{C}\right)$ \\
\hline $0 \mathrm{~A}, 0 \mathrm{~Hz}$ & 624 & 483 & 141 \\
$10 \mathrm{~A}, 5 \mathrm{~Hz}$ & 619 & 481 & 138 \\
$10 \mathrm{~A}, 10 \mathrm{~Hz}$ & 608 & 480 & 128 \\
$10 \mathrm{~A}, 15 \mathrm{~Hz}$ & 611 & 482 & 129 \\
\hline
\end{tabular}

and the temperature difference curves between the two positions. The temperature of the central thermocouple corresponding to the minimum point of the temperature difference curve is defined as the $T_{\text {coh }}$ of the alloy. As shown in Figs. 9 and 11 , the $T_{\text {coh }}$ of the AXJ530 alloy under the action of the low-frequency alternating magnetic field was significantly reduced and the lowest of $597{ }^{\circ} \mathrm{C}$ at the current frequency of $10 \mathrm{~Hz}$. Also, as shown in Fig. 9, the difference between the center temperature $\left(T_{\mathrm{c}}\right)$ and edge temperature $\left(T_{\mathrm{e}}\right)$ was reduced after applying an electromagnetic field outside the graphite crucible, and larger the current frequency, smaller 

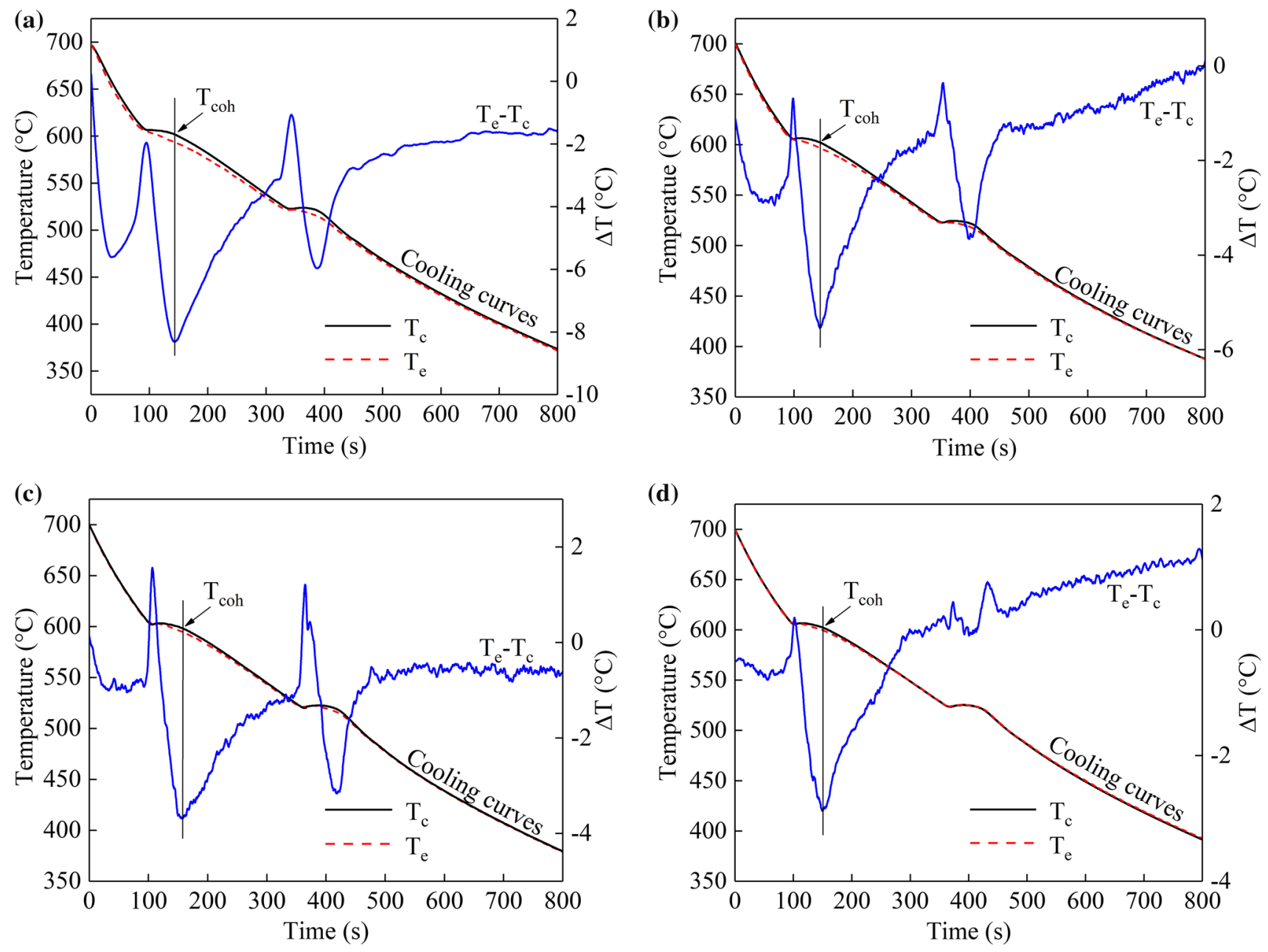

Fig. 9 DTA curves of AXJ530 alloy under different magnetic field conditions: a 0 A, $0 \mathrm{~Hz}$; b $10 \mathrm{~A}, 5 \mathrm{~Hz}$; $10 \mathrm{~A}, 10 \mathrm{~Hz}, \mathbf{d} 10 \mathrm{~A}, 15 \mathrm{~Hz}$

was the difference between both the temperatures. The maximum difference between $T_{\mathrm{e}}$ and $T_{\mathrm{c}}$ under natural conditions was $8.5^{\circ} \mathrm{C}$. However, at magnetic field frequencies of $10 \mathrm{~Hz}$ and $15 \mathrm{~Hz}$, the maximum difference between the two was 3.7 and $3{ }^{\circ} \mathrm{C}$, respectively. These results indicate that the action of the electromagnetic force can enhance the convection of the melt and tend to homogenize its temperature.

The alloy solid fraction curves drawn by the "Newton baseline method" [12] and the time information of each solid phase fraction node are shown in Fig. 10 and Table 2. The principle of "Newton baseline method" to define the solid fraction of an alloy is shown in Eq. (3). Among these, cc represents the cooling curve, $b_{1}$ represents a baseline, and $t_{1}$ and $t_{\mathrm{s}}$ are times corresponding to the start of solidification and the end of solidification, respectively. As per the information presented in the table in combination with the "Clyne-Davies" hot crack prediction model, the HTS coefficient under different magnetic field conditions was calculated, and the value of $\mathrm{CSC}_{t}$ is shown in Fig. 11. After the application of the low-frequency alternating magnetic

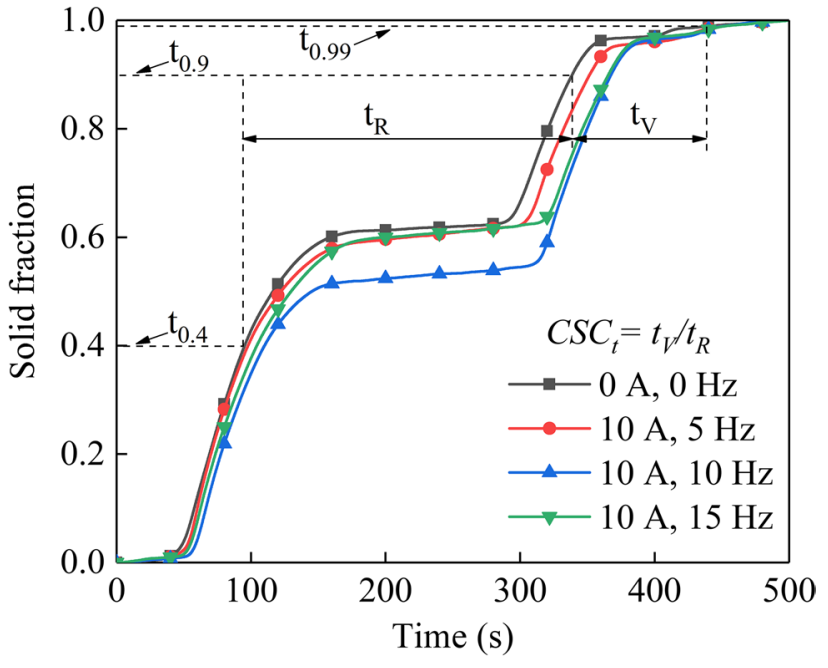

Fig. 10 Solidification time-solid fraction curves of AXJ530 alloy

field, the HTS of the alloy decreased first and then increased, which is basically the same as the trend for $T_{\text {coh }}$. Among 
Table 2 Thermal analysis results of AXJ530 alloys under different conditions

\begin{tabular}{lllrl}
\hline $\begin{array}{l}\text { Magnetic field } \\
\text { conditions }\end{array}$ & $t_{0.99}(\mathrm{~s})$ & $t_{0.9}(\mathrm{~s})$ & $t_{0.4}(\mathrm{~s})$ & $\begin{array}{l}\text { Eutectic } \\
\text { phases fraction } \\
(\%)\end{array}$ \\
\hline $0 \mathrm{~A}, 0 \mathrm{~Hz}$ & 442.8 & 338.7 & 95.2 & 37.6 \\
$10 \mathrm{~A}, 5 \mathrm{~Hz}$ & 451.9 & 351.7 & 97.6 & 39.5 \\
$10 \mathrm{~A}, 10 \mathrm{~Hz}$ & 452.0 & 367.6 & 109.9 & 46.8 \\
$10 \mathrm{~A}, 15 \mathrm{~Hz}$ & 453.7 & 365.7 & 104.2 & 38.8 \\
\hline
\end{tabular}

them, the alloy had the lowest $\mathrm{CSC}_{\mathrm{t}}$ of 0.33 when the current frequency was $10 \mathrm{~Hz}$. In addition, by observing and comparing the solid fraction curves under different conditions, the proportion of eutectic phase to solid fraction increased after the application of alternating magnetic field, and the proportion of eutectic phase to solid fraction was the largest when the current frequency was $10 \mathrm{~Hz}$. As the mass of alloy used in each experiment is the same, it can be concluded that the number of eutectic phases of the AXJ530 alloy increased under the action of low-frequency alternating magnetic field.

$f_{\mathrm{s}}=\frac{\int_{t_{1}}^{t}\left[\left(\frac{\mathrm{d} T}{\mathrm{~d} t}\right)_{c c}-\left(\frac{\mathrm{d} T}{\mathrm{~d} t}\right)_{b l}\right] \mathrm{d} t}{\int_{t_{1}}^{t_{\mathrm{s}}}\left[\left(\frac{\mathrm{d} T}{\mathrm{~d} t}\right)_{c c}-\left(\frac{\mathrm{d} T}{\mathrm{~d} t}\right)_{b l}\right] \mathrm{d} t}$

Based on the above experimental results, the low-frequency alternating magnetic field had a significant effect on the solidification behavior of the alloy. When a coil with alternating current was placed outside the graphite crucible, the coil produced an alternating magnetic field. Then, the induced current was generated in the metal liquid in the alternating magnetic field, and higher the frequency of the current, stronger was the induced current. The studies by Wang et al. show that $[33,34]$ with the decrease in temperature, the atomic group formed at the initial stage of solidification was crushed by the induced current to prevent further nucleation and growth. Moreover, higher the magnetic current frequency, stronger was the induced current generated in the molten metal and stronger the ability of the current to penetrate the atomic group. However, as the temperature continued to decrease and the degree of subcooling increased, a large number of nucleation sites were simultaneously generated in the metal melt and began to grow. The induced current generated by the alternating magnetic field could suppress the crystallization of the metal melt to lower the precipitation temperature of the primary phase. Meanwhile, the existing research $[8,35]$ shows that larger the solidification temperature range of the alloy, longer the alloy stays in the solid-liquid two-phase region and greater is the probability of hot tearing of the alloy. Therefore, after the application of electromagnetic field, the precipitation

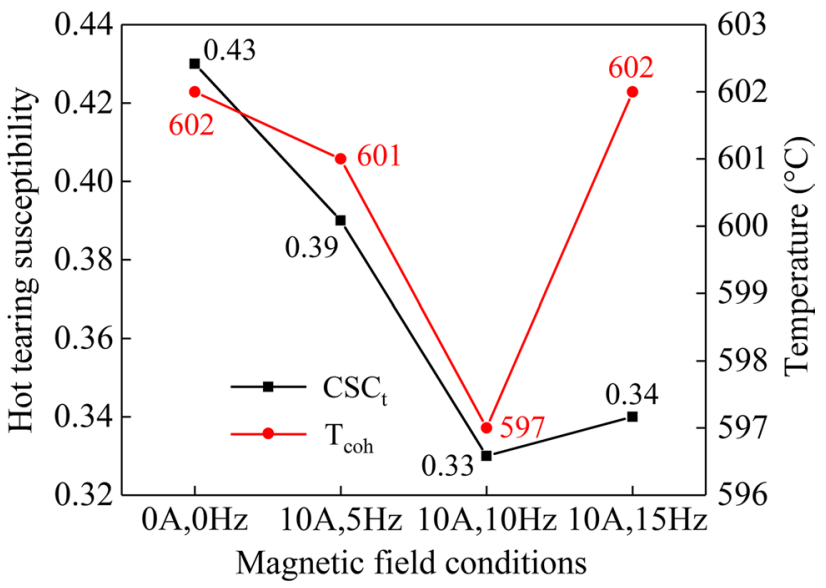

Fig. $11 \mathrm{CSC}_{\mathrm{t}}$ and $T_{\text {coh }}$ of AXJ530 alloy under different magnetic fields

temperature of $\alpha-\mathrm{Mg}$ in the alloy was significantly lowered, thereby shortening the solidification temperature interval of the alloy and lowering the HTS of the alloy. In addition, the electromagnetic interaction between the alternating magnetic field and induced current produced an electromagnetic force that pressed or pulled the metal away from the axis in the radial direction, thereby causing regular fluctuations in the melt. This phenomenon enhanced the convection of the molten metal during the solidification process to homogenize the melt temperature and even break the dendritic structure, thus hindering the dendrite growth to reduce the $T_{\text {coh }}$. The decrease in $T_{\text {coh }}$ increased the free feeding time of the alloy melt, which could better feed and heal the crack to reduce the chance of hot tearing. However, when the current frequency reached $15 \mathrm{~Hz}$, the induced current in the melt generated excessive Joule heat, which caused the cooling rate of the alloy to slow down and lower the subcooling and nucleation rate of the alloy. Therefore, the nascent tissue under these conditions coarsened and led to an increase in $T_{\text {coh. }}$. This phenomenon reduced the free feeding time of the alloy melt and increased the difficulty of feeding the low melting eutectic relative crack. When the current frequency was too high, HTS of the alloy also increased. The effect of the alternating magnetic field on the melt at a certain instant is shown in Fig. 12.

\subsection{Microscopic Analysis}

Under the action of a magnetic field, the primary dendritic structure broke under the forced convection caused by the magnetic field and the broken dendrites flowed with the melt to other locations to become new nucleation points, which shortened the primary dendrite length and refined the structure of the alloy $[18,36]$. Figure 13 shows the optical microstructure of AXJ530 alloy under different magnetic fields. 


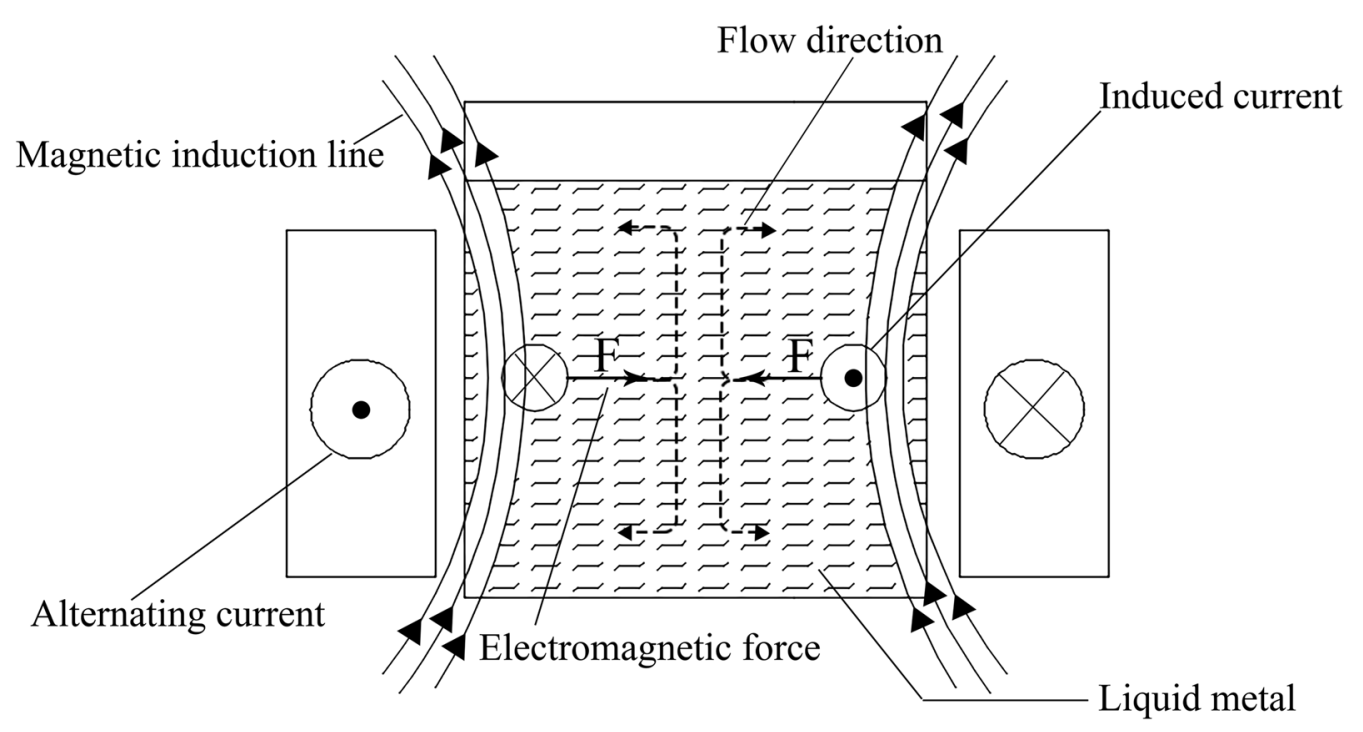

Fig. 12 Schematic of the action of alternating magnetic field on the melt at a certain instant

As shown in the figure, the alloy structure exhibited a coarse dendritic shape in the absence of magnetic field. After the application of magnetic field, as the frequency of the current increased, the dendritic and elongated structures in the alloy were continuously refined and gradually transitioned to a rose or equiaxed shape. However, the alloy structure at the current frequency of $15 \mathrm{~Hz}$ was slightly rougher than that at $10 \mathrm{~Hz}$.
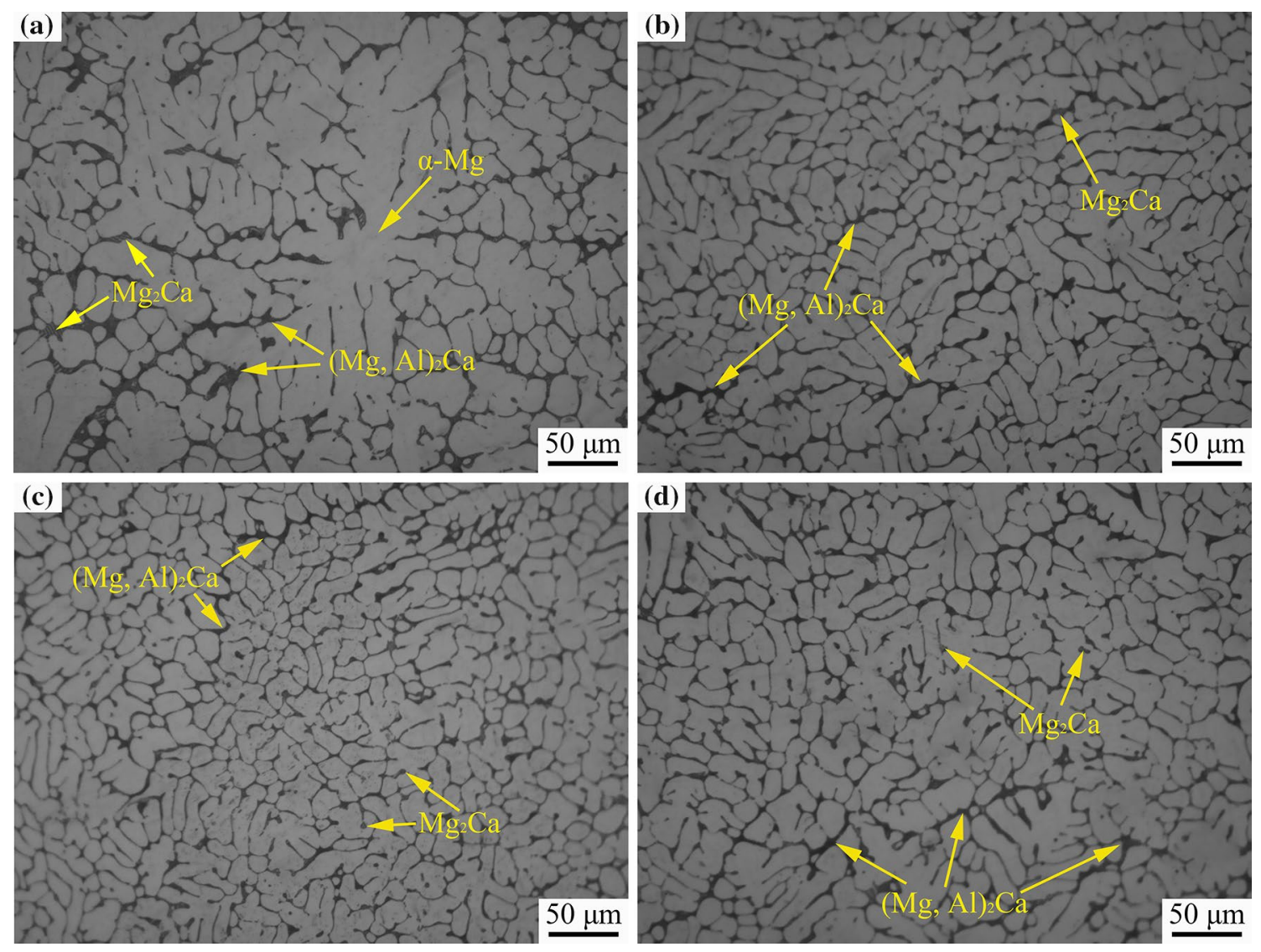

Fig. 13 Microstructures of AXJ530 alloy under different magnetic field conditions: a 0 A, $0 \mathrm{~Hz}$; b $10 \mathrm{~A}, 5 \mathrm{~Hz}$; c $10 \mathrm{~A}, 10 \mathrm{~Hz}, \mathbf{d} 10 \mathrm{~A}, 15 \mathrm{~Hz}$ 
The previous studies [37-39] have shown that the content and type of phases in the alloy can significantly affect the properties of the alloy, and it is one of the factors affecting HTS. Figure 14 shows the cracks morphology and feeding structure of the alloys under different magnetic field conditions, as obtained under scanning electron microscopy (SEM). The width and depth of the cracks of the casting were significantly reduced under the action of the magnetic field and the crack volume decreased with an increase in the current frequency. Among these, when the current frequency was $10 \mathrm{~Hz}$, the crack volume was the smallest. In combination with the existing literature and energy detection spectrum analysis results (Fig. 15), the river-like traces near the crack were the $\mathrm{C} 36$ and the $\mathrm{C} 14$ eutectic structures. The large number of shrinkage traces in Fig. 14c suggests that a large number of cracks generated during the solidification process were healed by the eutectic structure, and the eutectic structure involved in the feeding was clearly increased. These results are same as the analysis of the solid fraction curves. Based on the theory mentioned above, a large number of $\alpha-\mathrm{Mg}$ phases simultaneously nucleated in a short time. The high super-cooling at this time caused the grains to grow rapidly and a large number of solute elements also moved toward the grain boundary, which greatly reduced the solute content in the matrix. Moreover, the incomplete or broken dendrites dispersed in the melt were also advantageous for improving the morphology and distribution of the second phase, so that the second phase distribution became uniform and continuous, and the volume fraction was increased. When the frequency reached $15 \mathrm{~Hz}$, the increase in Joule heat generated by the induced current caused the undercooling of the alloy melt to decrease along with the decrease in the nucleation rate. At the same time, the decrease in the cooling rate caused the rate of grain growth to decrease, and the solubility of the solute element in the matrix increased, thereby reducing the volume fraction of the eutectic phase. Correspondingly, the crack volume of the casting at this frequency also increased. In addition, this is also the reason that $T_{\text {coh }}$ rose again at the current frequency of $15 \mathrm{~Hz}$.
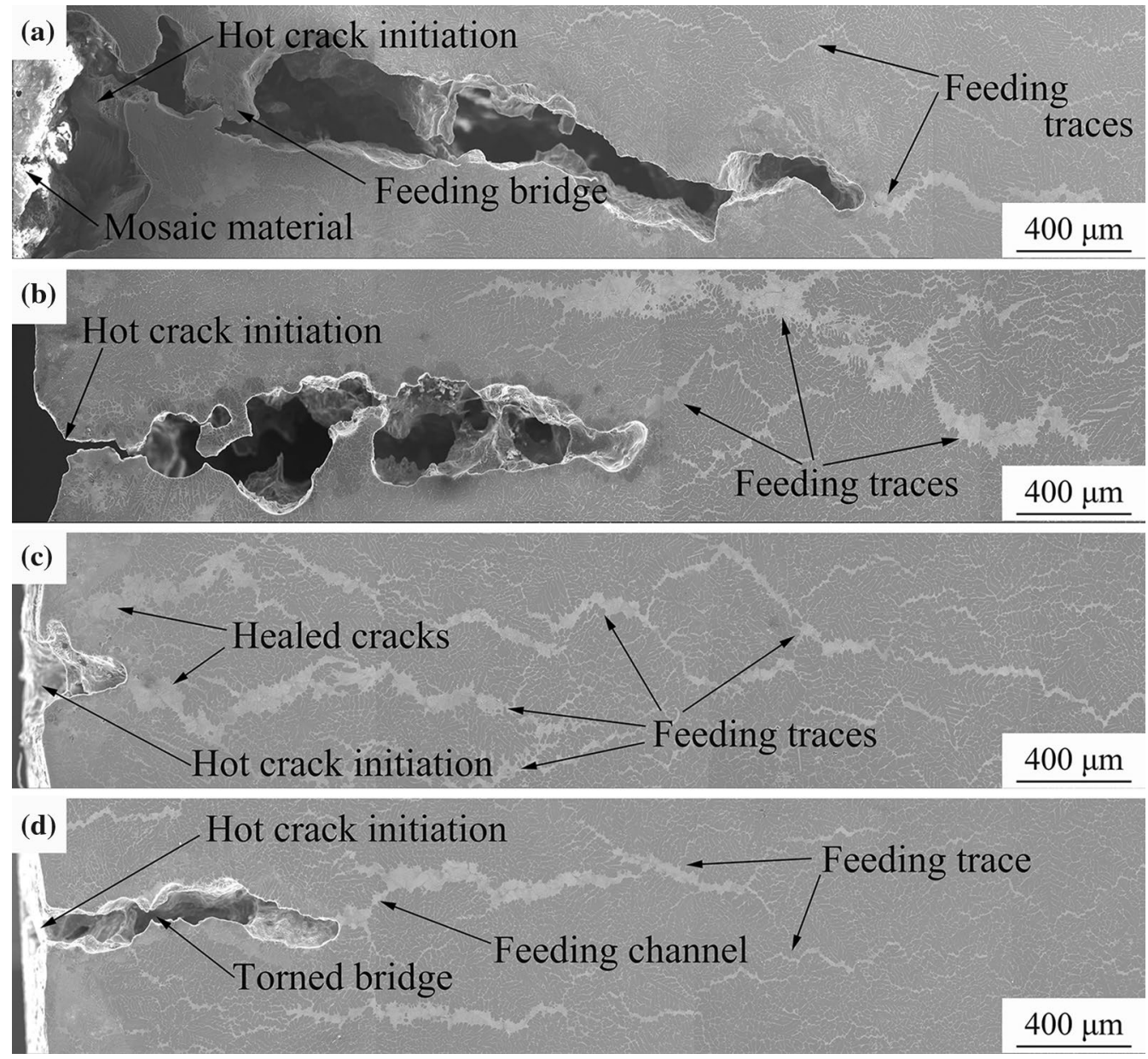

Fig. 14 Microstructure images near the cracks of AXJ530 alloy under different magnetic field conditions: a $0 \mathrm{~A}, 0 \mathrm{~Hz}$; b $10 \mathrm{~A}, 5 \mathrm{~Hz}$; c $10 \mathrm{~A}$, $10 \mathrm{~Hz}, \mathbf{d ~} 10 \mathrm{~A}, 15 \mathrm{~Hz}$ 

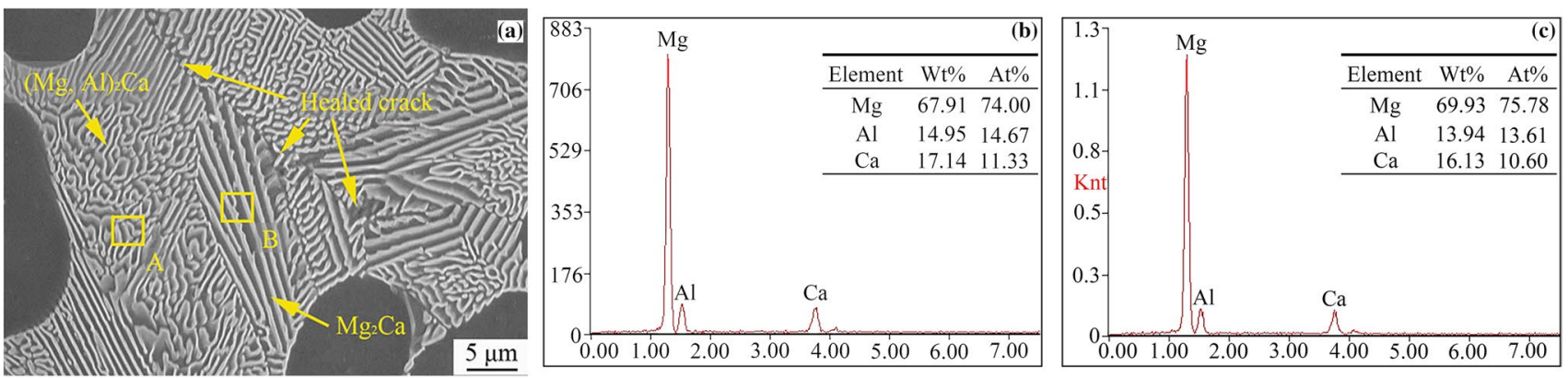

Fig. 15 Partially enlarged eutectic phase morphology image a of AXJ530 alloy, b, c their EDS analysis results

Therefore, as per the above experimental results, the dendritic structure of the alloy was significantly reduced under the action of magnetic field, and the length of the dendrite was shortened and gradually became an equiaxed structure, which remarkably refined the microstructure. Comparing the two microstructures, the change in the microstructure optimized the feeding channel of the low melting eutectic phase in the late solidification stage. As shown in Fig. 16, a narrow gap was formed between the long dendritic structures in the alloy when no magnetic field was applied. Compared to equiaxed structure, residual liquid phase needs to be supplemented for a longer length and has only one feeding channel. At this time, the flow and replenishment of the residual liquid phase under natural convection conditions were difficult, and it was easy to generate hot cracks. However, under the action of the low-frequency alternating magnetic field, the dendritic structure in the alloy was broken to shorten the length of the primary dendrite, which reduced the distance and difficulty of the residual liquid phase to feed. Studies
$[40,41]$ have shown that an equiaxed structure is more conducive to the flow of low melting phases between the crystals to eliminate segregation. When the microstructure of the structure tended to be equiaxed, the eutectic phase exhibited a uniform network distribution. The inter-grain feeding channels became increasingly shorter, which was more conducive to the flow and feeding of the residual liquid phase in the late solidification to heal the crack. At the same time, the electromagnetic force generated by the interaction of the magnetic field with the induced current enhanced the convection and homogenized the temperature in the melt, which enhanced the flow and the compensation ability of the eutectic phase in the late solidification stage. The HTS of the alloy was also reduced. However, when the current frequency reaches $15 \mathrm{~Hz}$, excessive Joule heat slowed down the cooling rate and subcooling of the alloy and reduced the nucleation rate. The braking effect and thermal action of the low-frequency alternating magnetic field on the melt have different effects on the HTS of the alloy. The HTS of (a)

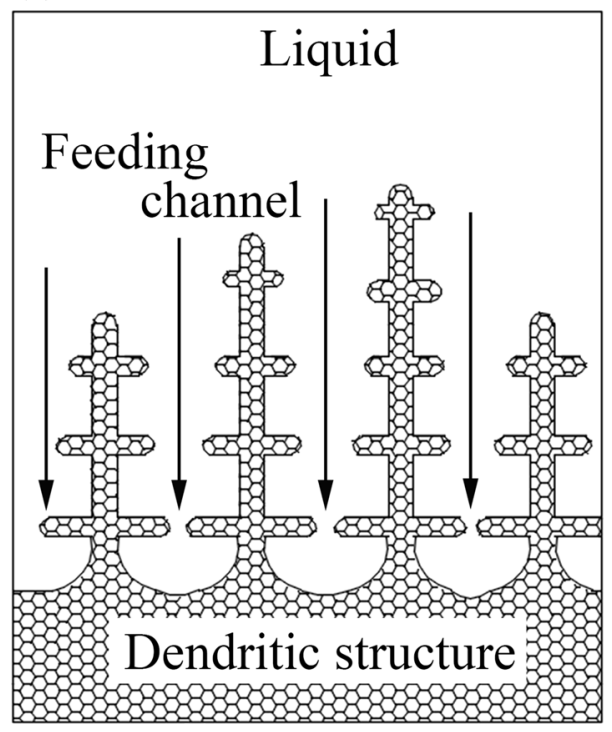

(b)

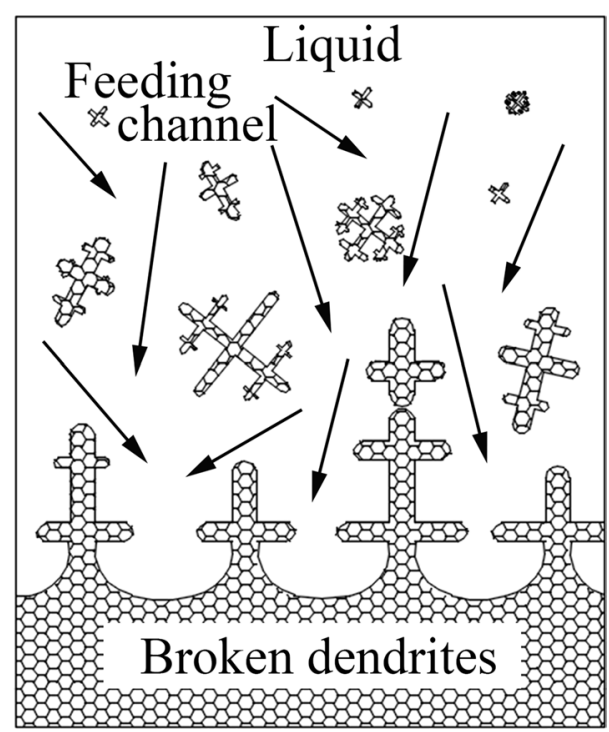

Fig. 16 Schematic of the feeding behavior of different microstructures: a natural condition, $\mathbf{b}$ magnetic field condition 
the alloy did not always decrease with the increase in the frequency of the alternating magnetic field. Excessive magnetic field frequency made a dominant thermal effect on the melt. At this time, the grain coarsening caused by the decrease in the cooling rate and the degree of subcooling was stronger than the grain refinement caused by the magnetic field, which caused coarsening of the alloy structure and increased the HTS of the alloy.

\section{Conclusions}

1. Under the low-frequency alternating magnetic field, the hot tearing susceptibility of the AXJ530 alloy decreased first and then increased with the increase in the frequency of the magnetic field. Under the experimental conditions, the order of the HTS of AXJ530 alloy at each magnetic field frequency was $10 \mathrm{~A} 10 \mathrm{~Hz}<10 \mathrm{~A}$ $15 \mathrm{~Hz}<10$ A $5 \mathrm{~Hz}<0$ A $0 \mathrm{~Hz}$.

2. The alternating magnetic field produced an induced current in the melt. The induced current broke down the atomic group at the beginning of solidification, thereby lowering the precipitation temperature of $\alpha-\mathrm{Mg}$ and shortening the solidification temperature range of the alloy.

3. The low-frequency alternating magnetic field strengthened the forced convection of the melt, broke the dendrites, refined the grains, and decreased the dendrite coherence temperature of the alloy. Thereby, the flow of the residual liquid phase in the late solidification was promoted, and its feeding channel was optimized, and the hot tearing susceptibility of the alloy was lowered.

4. When the frequency of the magnetic field was $15 \mathrm{~Hz}$, there was a dominant thermal effect on the melt. Excessive Joule heat reduced the undercooling, coarsened the microstructure, and increased the dendritic coherence temperature of the alloy. The hot tearing susceptibility of the alloy also increased.

Acknowledgements This work is financially supported by the LiaoNing Revitalization Talents Program (No. XLYC1807021) and the Innovation Talent Program in Sciences and Technologies for Young and Middle-aged Scientists of Shenyang (No. RC180111) and the Doctoral Scientific Research Foundation of Liaoning Province (No. 51504153).

\section{References}

[1] T.M. Pollock, Science 328, 986 (2010)

[2] B.L. Mordike, T. Ebert, Mater. Sci. Eng. A 302, 37 (2001)

[3] A.A. Luo, J. Magnes. Alloys 1, 2 (2013)

[4] Y. Lou, X. Bai, L. Li, Trans. Nonferrous Met. Soc. China 21, 1247 (2011)
[5] J. Bai, Y.S. Sun, F. Xue, S. Xue, J. Qiang, W.J. Tao, H.F. Liu, Acta Metall. Sin. (in Chinese) 42, 1267 (2006)

[6] A.A. Luo, A.K. Sachdev, B.R. Powell, China Foundry 7, 463 (2010)

[7] G. Cao, S. Kou, Metall. Mater. Trans. A 37, 3647 (2006)

[8] F. Wang, H.K. Dong, Z. Wang, P.L. Mao, Z. Liu, Acta Metall. Sin. (in Chinese) 53, 211 (2017)

[9] F. Wang, D. Ma, Z. Wang, P.L. Mao, Z. Liu, Acta Metall. Sin. 52 , $1115(2016)$

[10] P. Liu, H. Jiang, Z. Cai, Q. Kang, Y. Zhang, J. Magnes. Alloys 4, 188 (2016)

[11] M.B. Yang, D.Y. Wu, M.D. Hou, F.S. Pan, Trans. Nonferrous Met. Soc. China 25, 721 (2015)

[12] Z. Liu, S.B. Zhang, P.L. Mao, F. Wang, Mater. Sci. Technol. 30, $1214(2014)$

[13] Z.Q. Wei, Y. Wang, Z. Liu, Mater. Sci. Technol. 34, 2001 (2018)

[14] Z. Wei, Z. Liu, Y. Wang, Mater. Res. Express 6, 076570 (2019)

[15] Y. He, Q. Li, W. Liu, Mater. Lett. 65, 1226 (2011)

[16] L. Zhang, P.H. Hu, Q. Zhou, W. Zhan, F. Jin, Mater. Lett. 193, 224 (2017)

[17] J.C. Jie, Q.C. Zou, J.L. Sun, Y. Liu, T. Wang, T.J. Li, Acta Mater. 72, 57 (2014)

[18] F. Cao, F. Yang, H. Kang, C. Zou, T. Xiao, W. Huang, T. Wang, J. Cryst. Growth 450, 91 (2016)

[19] B. Wang, Y.S. Yang, M.L. Sun, Trans. Nonferrous Met. Soc. China 18, 536 (2010)

[20] S. Guo, J. Cui, Q. Le, Z. Zhao, Mater. Lett. 59, 1841 (2005)

[21] F. Tang, A.L. Lu, J.F. Mei, H.Z. Fang, J. Mater. Process. Technol. 74, 255 (1998)

[22] S. Wu, A.L. Lu, H.Y. Zhao, H.Z. Fang, F. Tang, J. Mater. Process. Technol. 328, 133 (2002)

[23] Z. Li, D. Luo, T. Li, Z. Cao, Mater. Mech. Eng. 33, 29 (2009)

[24] X. Liu, J. Cui, F. Yu, J. Mater. Sci. 39, 2935 (2004)

[25] Z. Wang, Y.D. Huang, A. Srinivasan, Z. Liu, F. Beckmann, K.U. Kainer, N. Hort, Mater. Des. 47, 90 (2013)

[26] Z. Wang, Y.D. Huang, A. Srinivasan, Z. Liu, F. Beckmann, K.U. Kainer, N. Hort, J. Mater. Sci. 49, 353 (2014)

[27] Y. Han, C.Y. Ban, Q.X. Ba, J.W. Cui, J. Northeast. Univ. 27, 991 (2006)

[28] Z. Wang, Y.Z. Li, F. Wang, Y. Huang, J. Song, P.L. Mao, Z. Liu, Trans. Nonferrous Met. Soc. China 26, 62 (2016)

[29] A. Noeppel, A. Ciobanas, X.D. Wang, K. Zaidat, Metall. Mater. Trans. B 41, 193 (2010)

[30] T.W. Clyne, G.J. Davies, Brit. Found. 74, 65 (1981)

[31] A. Suzuki, N.D. Saddock, J.W. Jones, T.M. Pollock, Acta Mater. 53, 2823 (2005)

[32] T.W. Clyne, M. Wolf, W. Kurz, Metall. Trans. B 13, 259 (1982)

[33] T. Wang, J. Xu, T. Xiao, H. Xie, J. Li, T. Li, Z. Cao, Phys. Rev. E 81, 042601 (2010)

[34] F. Yang, Z. Chen, F. Cao, K. Fan, H. Kang, W. Huang, Q. Yuan, T. Xiao, T. Fu, T. Wang, J. Mater. Sci. Technol. 10, 70 (2017)

[35] H.K. Dong, F. Wang, Z. Wang, J.K. Liu, Z. Liu, P.L. Mao, Mater. Res. Express 5, 036513 (2018)

[36] H. Li, J. Jie, H. Chen, P. Zhang, T. Wang, T. Li, Mater. Sci. Eng. A 624, 140 (2015)

[37] B.N. Du, Z.Y. Hu, L.Y. Sheng, D.K. Xu, Y.F. Zheng, T.F. Xi, Acta Metall. Sin. (Engl. Lett.) 31, 17 (2018)

[38] Z. Wang, Y.Z. Li, F. Wang, J.F. Song, Z. Liu, P.L. Mao, J. Mater. Eng. Perform. 25, 5530 (2016)

[39] H. Liu, H. Huang, J.P. Sun, C. Wang, J. Bai, A.B. Ma, X.H. Chen, Acta Metall. Sin. (Engl. Lett.) 32, 269 (2019)

[40] Y. Hou, Z.Q. Zhang, W.D. Xuan, J. Wang, J.B. Yu, Z.M. Ren, Acta Metall. Sin. (Engl. Lett.) 31, 681 (2018)

[41] Y.G. Tan, F. Liu, A.W. Zhang, D.W. Han, X.Y. Yao, W.W. Zhang, W.R. Sun, Acta Metall. Sin. (Engl. Lett.) 32, 1298 (2019) 